doi: https://doi.org/10.15407/dopovidi2019.03.072

УДК 523.681 .8

\title{
Е.П. Гуров, В.В. Пермяков
}

Институт геологических наук НАН Украины, Киев

E-mail: yevgeniy.gurov@gmail.com

\section{Хромферид в ударнорасплавленных породах кратера Эльгыгытгын на Чукотке (Россия)}

Представлено академиком НАН Украины П.Ф. Гожиком

\begin{abstract}
Акцессорная минерализация хромферида установлена в составе ударнорасплавленных пород импактного кратера Эльгыгытгын на Чукотке. Расплавные импактиты представлены массивными пузырчатыми породами со стекловатой матрищей и многочисленными включениями обломков ударнометаморфизованньх пород и минералов мишени кратера. Хромферид кристаллизуется в контракционных трещинах толщиной до 10 мкм в стекловатой матрище пород, а также на внутренней поверхности газовых пузырей. Состав хромферида из расплавньх импактитов соответствует составу эталонного минерала и отвечает кристаллохимической формуле $\mathrm{Fe}_{1,5} \mathrm{Cr}_{0,2}$ или $\mathrm{Fe}_{7} \mathrm{Cr}_{1}$. Ранее было установлено значительное обогащение ударнорасплавленных пород кратера Эльгыгытгын хромом за счет вещества ударника, в связи с чем вероятным основным источником хрома при образовании хромферида послужило вещество кратерообразующего астероида.
\end{abstract}

Ключевые слова: хромферид, импактный кратер, ударнорасплавленная порода, контракиионная трещина, астероид.

Акцессорная минерализация хромферида установлена в составе ударнорасплавленных пород кратера Эльгыгытгын на Чукотке. Хромферид как новый минеральный вид впервые определен и описан М.И. Новгородовой в породах золоторудных месторождений на Южном Урале и в Средней Азии [1, 2]. Согласно этим данным, минерал представляет собой упорядоченный нестехиометрический твердый раствор состава: $\mathrm{Fe}_{1,5} \mathrm{Cr}_{0,5-x}$, основу кристаллической структуры которого образует несовершенная кубическая ячейка с параметром $a_{0}=2,859 \pm 0,005 \AA[2]$.

Импактный кратер Эльгыгытгын диаметром 18 км образован 3,58 \pm 0,08 млн лет назад в толще вулканогенных пород Охотско-Чукотского Вулканического Пояса [3-6]. Кратер представлен в виде круговой депрессии, окруженной кольцевым валом высотой около 200 м. Породы вала представлены толщей лав и туфов липаритового и липарито-дацитового состава, которые не обнаруживают признаков ударного метаморфизма. Наиболее глубокую часть дна депрессии занимает оз. Эльгыгытгын диаметром 12 км, окруженное озерными террасами высотой до 80 м [3-5].

(C) Е.П. Гуров, В.В. Пермяков, 2019 
Импактные породы в кратере Эльгыгытгын на современном уровне эрозионного среза сохранились в переотложенном состоянии в озерных террасах в виде скоплений глыб и обломков. Импактиты представлены ударнорасплавленными породами, импактными стеклами и ударнометаморфизованными породами мишени. Расплавные импактиты сохранились в виде локальных скоплений, образованных за счет разрушения отдельных потоков ударного расплава, застывшего на внутренних склонах кратера. Обломки ударнометаморфизованных вулканогенных пород и стекловатые бомбы аэродинамической формы, образованные за счет разрушения полностью эродированного покрова выбросов, повсеместно распространены в террасовых отложениях [4, 5, 7]. В коренном залегании импактиты установлены в разрезе скважины 5101-1, пробуренной по программе International Continental Scientific Drilling Program под руководством проф. Х. Кеберля из Венского университета [8].

Хромферид установлен при электронно-микроскопическом изучении ударнорасплавленных пород из отложений террасы южного берега оз. Эльгыгытгын. Электронно-микроскопические исследования расплавных импактитов включали изучение микроструктур пород, химического состава стекловатой матрицы и кристаллитов, а также минералов включений и следов воздействия на них высокотемпературного ударного расплава. Исследования проведены на сканирующем электронном микроскопе JEOL JSM-6490LV с рентгеновской спектрометрической системой INCA Energy+ (Oxford Instruments). Работы выполнены в фазово-контрастном режиме отраженных электронов (BSEI).

Расплавные импактиты состоят из стекловатой или девитрифицированной матрицы, содержащей кристаллиты гиперстена и андезин-олигоклаза, а также газовые пузыри округлой и неправильной формы размером от 10-20 до 100-200 мкм. Внутренняя поверхность пузырей покрыта сложными агрегатами кристаллитов полевого шпата, изредка кристаллитами ромбического пироксена, а также позднего титаногематита, образующего идиоморфные кристаллиты и друзы. Минерализация на внутренней поверхности газовых пузырей свидетельствует о высокой интенсивности конденсационных процессов при образовании импактитов. Многочисленные включения в стекловатой матрице представлены ударнометаморфизованными минералами, среди которых преобладают диаплектовый кварц и лешательерит. Включения акцессорных и рудных минералов представены в различной степени резорбированными зернами ильменита, титаногематита, сфена и циркона с включениями бадделеита.

Хромферид наблюдается в виде агрегатов в открытых контракционных микротрещинах в стекловатой матрице, где он представлен в виде плотных масс, заполняющих отрезки микротрещин длиной до 20-30 мкм, или образует выделения неправильной формы на их стенках (рис. 1, $a$ ). Отдельные зерна хромферида имеют пластинчатую форму. Размеры и форма выделений минерала определяются формой заполняемых микротрещин и их шириной, составляющей от 1-2 до 5-6 мкм (см. рис. 1, б).

Вторая форма кристаллизации хромферида представлена зернами и агрегатами минерала, образованными на внутренней поверхности газовых пузырей. Изредка зерна и агрегаты хромферида наблюдаются на внутренней поверхности крупных вакуолей, содержащих растительные остатки (рис. 2, a). Выделения хромферида, кристаллизовавшиеся в пузырях в условиях свободного роста, образуют агрегаты пластинчатого строения размером до 10-15 мкм с толщиной отдельных ламелей около 0,5-1 мкм и диаметром до 10 мкм 

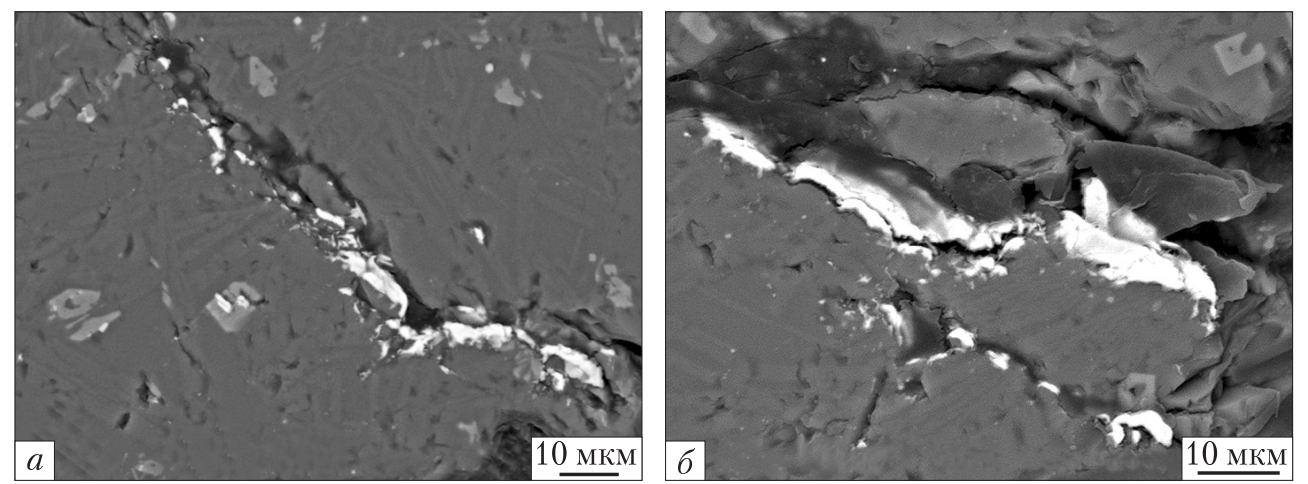

$\boldsymbol{P u c . ~ 1 . ~ К р и с т а л л и з а ц и я ~ х р о м ф е р и д а ~ в ~ к о н т р а к ц и о н н о и ̆ ~ т р е щ и н е ~ в ~ д е в и т р и ф и ц и р о в а н н о и ̆ ~ с т е к л о в а т о и ̆ ~}$ матрице расплавного импактита. В стекловатой матрице наблюдаются поперечные срезы скелетных кристаллитов гиперстена (серые на изображении) и агрегаты пластинчатых кристаллитов плагиоклаза (обр. Е-900-12): $a$ - хромферид заполняет узкие участки трещины и образует отдельные пластинчатые зерна на стенках трещины; $\sigma$ - выделение хромферида на стенках контракционной трещины. Разрывы агрегатов хромферида тонкой трещиной (в центре слева) свидетельствуют о продолжении рсширения трещины после выделения хромферида

(см. рис. 2, б). Важно отметить, что пластинчатое строение характерно для хромферида из золоторудных месторождений Южного Урала и в Средней Азии, где этот минерал был впервые описан [1, 2]. В таблице приведен состав хромферида из расплавных импактитов кратера Эльгыгытгын и, для сравнения, состав эталонного хромферида [2]. Главные элементы минерала представлены железом и хромом с атомным соотношением $\mathrm{Fe} / \mathrm{Cr}$ от 6,4 до 7,5 при среднем значении 7,0 , что соответствует этому соотношению в составе хромферида из золоторудных месторождений [2]. В составе некоторых зерен хромферида из кратера Эльгыгытгын установлено содержание до 0,15 \% (мас.) никеля. Примесь кремния в отдельных анализах предположительно может быть связана с влиянием матрицы. Формула хромферида из кратера Эльгыгытгын: $\mathrm{Fe}_{7} \mathrm{Cr}_{1}$ или $\mathrm{Fe}_{1,5} \mathrm{Cr}_{0,2}$ полностью соответствует формуле эталонного хромферида из золоторудных месторождений: $\mathrm{Fe}_{3} \mathrm{Cr}_{1-x}$, где $x=0,6$, или $\mathrm{Fe}_{7} \mathrm{Cr}[1]$, или $\mathrm{Fe}_{1,5} \mathrm{Cr}_{0,5-x}$, где $x=0,3$ [2].

Хромферид в ударнорасплавленных породах кратера Эльгыгытгын кристаллизуется в контракционных микротрещинах стекловатой матрицы и внутри газовых пузырей после

Состав хромферида из ударнорасплавленных пород кратера Эльгыгытгын (образцы 1, 2, данные микрозондового анализа) и состав эталонного хромферида (3)

\begin{tabular}{|l|c|c|c|}
\hline Элементы & 1 & 2 & 3 \\
\hline $\mathrm{Fe}$ & 86,85 & 87,00 & 88,91 \\
$\mathrm{Cr}$ & 11,65 & 12,98 & 11,30 \\
$\mathrm{Si}$ & 1,29 & - & - \\
Сумма & 99,79 & 99,98 & 100,21 \\
\hline
\end{tabular}

Примечание. 1 - обр. Е-900-12, среднее по пяти анализам; 2 - обр. Е-900-1, среднее по четырем анализам; 3 - хромферид по [2]. полного затвердевания ударного расплава и понижения его температуры, вызывающего образование открытых микротрещин. Температура кристаллизации хромферида в расплавных импактитах может быть приблизительно оценена по аналогии с температурами образования хромферида из золоторудных месторождений, где они составляют $\leqslant 400{ }^{\circ} \mathrm{C}[2]$. В связи с отсутствием следов гидротермаль- 

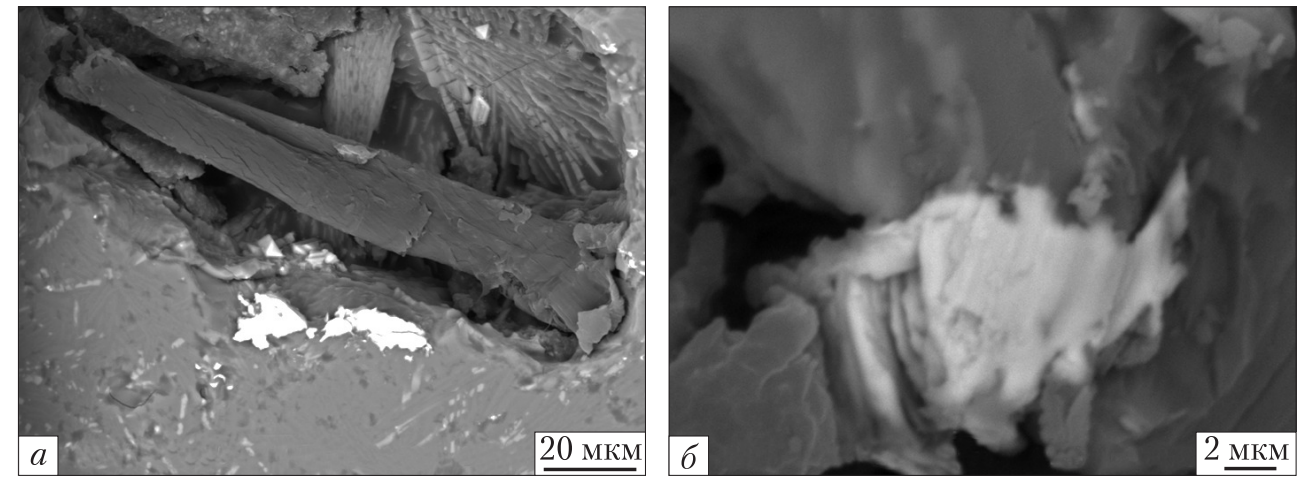

Puc. 2. Образования хромферида в газовых пузырях: $a$ - кристаллизация хромферида на внутренней поверхности газового пузыря, содержащего частицу палеофлоры, захваченной ударным расплавом. В верхней части снимка - агрегаты полевых шпатов, выстилающих внутреннюю поверхность пузыря (обр. E-900-1); б - пластинчатое строение хромферида на внутренней поверхности пузыря (обр. Е-900-12)

ных изменений в ударнорасплавленных породах кратера Эльгыгытгын [4, 9] предполагается кристаллизация хромферида из газовой фазы. Условия локализации зерен и агрегатов минерала в контракционных трещинах и на внутренней поверхности газовых вакуолей могут служить подтверждением этого процесса. Форма агрегатов и зерен хромферида из газовых пузырей свидетельствует об их росте в условиях свободного пространства.

Геохимические исследования расплавных импактитов и пород мишени кратера Эльгыгытгын, проведенные с целью определения состава ударника, позволили установить относительное обогащение ударнорасплавленных пород относительно пород мишени некоторыми сидерофильными элементами и платиноидами. Значительное повышение содержания хрома в импактитах по сравнению с его содержанием в вулканогенных породах мишени кратера при отсутствии значимого обогащения ударнорасплавленных пород никелем и кобальтом дает основания предполагать ахондритовый, возможно, уреилитовый, состав астероида, образовавшего кратер [4, 5, 10, 11].

При изучении состава образцов ударнорасплавленных пород из скважины 5101-1 и террасовых отложений оз. Эльгыгытгын также было доказано их обогащение хромом, в меньшей степени никелем [12]. Однако проведенные этими исследователями определения содержания в импактитах элементов платиновой группы и ${ }^{187} \mathrm{Os} /{ }^{188} \mathrm{Os}$ отношения послужили основанием для заключения о том, что наиболее вероятным ударником кратера Эльгыгытгын явился обыкновенный хондрит [12].

Противоречия в определении состава ударника картера Элгыгытгын - ахондрит или обыкновенный хондрит, - вероятно, были разрешены в работе [13] в результате изучения изотопии хрома и относительного содержания $\varepsilon^{54} \mathrm{Cr}$ в составе образцов ударнорасплавленных пород и импактных стекол из кратера. В качестве вероятного ударника был предложен астероид F-типа, представляющий собой смесь материала уреилита (70-80 \%) и обыкновенного хондрита (20-30\%) [13].

Таким образом, кратерообразующий астероид, определивший обогащение ударнорасплавленных пород хромом относительно пород мишени, послужил источником этого элемента при образовании хромферида в импактитах кратера Эльгыгытгын. Обнаружение 
хромферида в ударнорасплавленных породах кратера Эльгыгытгын является первой находкой этого минерала в породах земных импактных структур.

\section{ЦИТИРОВАННАЯ ЛИТЕРАТУРА}

1. Новгородова М.И. Самородные металлы в гидротермальных рудах. Москва: Наука, 1983. 287 с.

2. Новгородова М.И., Горшков А.И., Трубкин Н.В., Цепин А.И., Дмитриева М.Т. Новые природные интерметаллические соединения железа и хрома - хромферид и ферхромид. Зап. Всесоюз. минералог. об-ва.1986. 115, вып. 3. С. 355-360.

3. Гуров Е.П., Вальтер А.А., Гурова Е.П., Серебренников А.И. Взрывной метеоритный кратер Эльгыгытгын на Чукотке. Докл. АН СССР. 1978. 240, № 6. С. 1407-1410.

4. Гуров Е.П., Гурова Е.П. Геологическое строение и вещественный состав пород импактных структур. Киев: Наук. думка, 1991. 160 с.

5. Gurov E.P., Koeberl C. Shocked rocks and impact glasses from the El'gygytgyn impact structure, Russia. Meteorit. Planet. Sci. 2004. 39. P. 1495-1508.

6. Layer P.V. ${ }^{40}$ Argon ${ }^{39}$ Argon-age of the El'gygytyn event, Chukotka, Russia. Meteorit. Planet. Sci. 2000. 35. P. 591-599.

7. Гуров Е.П., Гурова Е.П., Рябенко В.А. Импактиты и стекловатые бомбы метеоритного кратера Эльгыгытгын на Чукотке. Изв. АН СССР. Сер. геол. 1980. № 1. С. 54-61.

8. Koeberl C., Pittarello L., Reimold W.U., Raschke U., Brigham-Grette J., Melles M., Minyuk M. El'gygytgyn impact crater, Chukotka, Arctic Russia: Impact cratering aspects of the 2009 ICDP drilling project. Meteorit. Planet. Sci. 2013. 48. P. 1108-1129.

9. Pittarello L., Koeberl C. Petrography of impact glasses and melt breccias from the El'gygytgyn structure, Russia. Meteorit. Planet. Sci. 48. P. 1236-1250.

10. Val'ter A.A., Barchuk I.F., Bulkin V.S., Ogorodnic A.F., Kotishevskaya E.Y. The El'gygytgyn meteorite: Probable composition. Sov. Astronom. Let. 1982. 8. P. 115-120.

11. Kapustkina I.G., Feldan V.I., Kolesov G.M. Behaviour of some meteoritic indicator elements in process of impact melt degassing (abstract). Lunar Planet. Sci. Conf. 1985. 16. P. 422.

12. Goderis S., Wittmann A., Zaiss J., Elburg M., Ravizza G., Vanhaecke F., Deutsch A., Claeys P. Testing the ureilite projectile hypothesis for the El'gygytgyn impact: Determination of siderophile element abundance and Os isotope ratios in ICDR drill core samples and melt rocks. Meteorit. Planet. Sci. 2013. 48. P. 1296-1324.

13. Foriel J., Moynier F., Schulz T., Koeberl C. Chromium isotope anomaly in an impactite sample from the El'gygytgyn structure, Russia: Evidence for a ureilite projectile? Meteorit. Planet. Sci. 2013. 48. P. 1339-1350.

Поступило в редакцию 12.12 .2018

\section{REFERENCES}

1. Novgorodova, M. I. (1983). Native metals in hydrothermal ores. Moskow: Nauka (in Russian).

2. Novgorodova, M. I., Gorschkov, A. I., Trubkin, N. V., Tsepin, A. I. \& Dmitrieva, M. T. (1986). New natural Intermetallic compounds of iron and chromium - chromferide and ferchromide. Zap. Vsesoyuz. Mineralog. Ob-va, 115, Iss. 3, pp. 355-360 (in Russian).

3. Gurov, E. P., Valter, A. A., Gurova, E. P. \& Serebrennikov, A. I. (1978). Impact meteorite crater El'gygytgyn in Chukotka. Dokl. AN SSSR, 240, pp.1407-1410 (in Russian).

4. Gurov, E. P. \& Gurova, E. P. (1991). Geological structure and rock composition of impact structures. Kiev: Naukova Dumka (in Russian).

5. Gurov, E. P. \& Koeberl, C. (2004). Shocked rocks and impact glasses from the El'gygytgyn impact structure, Russia. Meteorit. Planet. Sci., 39, pp. 1495-1508.

6. Layer, P. V. (2000). ${ }^{40}$ Argon ${ }^{39}$ Argon-age of the El'gygytyn event, Chukotka, Russia. Meteorit. Planet. Sci., 35, pp. 591-599.

7. Gurov, E. P., Gurova, E. P. \& Ryabenko, V. A. (1980). Impactites and glassy bombs of the El'gygytgyn crater in Chukotka. Izv. AN SSSR. Ser. geol., No. 1, pp. 54-61 (in Russian). 
8. Koeberl, C., Pittarello, L., Reimold, W. U., Raschke, U., Brigham-Grette, J., Melles, M. \& Minyuk, M. (2013). El'gygytgyn impact crater, Chukotka, Arctic Russia: Impact cratering aspects of the 2009 ICDP drilling project. Meteorit. Planet. Sci., 48, pp. 1108-1129.

9. Pittarello, L. \& Koeberl, C. (2013). Petrography of impact glasses and melt breccias from the El'gygytgyn structure, Russia. Meteorit. Planet. Sci., 48, pp. 1236-1250.

10. Val'ter, A. A., Barchuk, I. F., Bulkin, V. S., Ogorodnic, A. F. \& Kotishevskaya, E. Y. (1982). The El'gygytgyn meteorite: Probable composition. Sov. Astronom. Let., 8, pp. 115-120.

11. Kapustkina, I. G., Feldman, V. I. \& Kolesov, G. M. (1985). Behaviour of some meteoritic indicator elements in process of impact melt degassing (abstract). Lunar Planet. Sci. Conf., 16, p. 422.

12. Goderis, S., Wittmann, A., Zaiss, J., Elburg, M., Ravizza, G., Vanhaecke, F., Deutsch, A. \& Claeys, P. (2013). Testing the ureilite projectile hypothesis for the El'gygytgyn impact: Determination of siderophile element abundance and Os isotope ratios in ICDR drill core samples and melt rocks. Meteorit. Planet. Sci., 48, pp. 1296-1324.

13. Foriel, J., Moynier, F., Schulz, T. \& Koeberl, C. (2013). Chromium isotope anomaly in an impactite sample from the El'gygytgyn structure, Russia: Evidence for a ureilite projectile? Meteorit. Planet. Sci., 48, pp. 1339-1350.

Received 12.12.2018

\section{С.П. Гуров, В.В. Пермяков}

Інститут геологічних наук НАН України, Київ

E-mail: yevgeniy.gurov@gmail.com

\section{ХРОМФЕРИД В УДАРНОРОЗПЛАВЛЕНИХ ПОРОДАХ КРАТЕРА ЕЛЬГИГИТГИН НА ЧУКОТЦІ (РОСІЯ)}

Акцесорна мінералізація хромфериду встановлена у складі ударнорозплавлених порід кратера Ельгигитгин на Чукотці. Розплавні імпактити представлені масивними пухирчастими породами зі склуватою матрицею та численними включеннями уламків ударнометаморфізованих порід і мінералів мішені кратера. Хромферид кристалізується у контракційних тріщинах завтовшки до 10 мкм у склуватій матриці порід, а також на внутрішній поверхні газових міхурів. Склад хромфериду з розплавних імпактитів відповідає складу еталонного мінералу та кристалохімічній формулі $\mathrm{Fe}_{1,5} \mathrm{Cr}_{0,2}$ або $\mathrm{Fe}_{7} \mathrm{Cr}_{1}$. Раніше було встановлено значне збагачення ударнорозплавлених порід кратера Ельгигитгин хромом за рахунок речовини ударника, у зв'язку з чим імовірним головним джерелом хрому під час утворення хромфериду була речовина кратероутворюючого астероїда.

Ключові слова: хромферид, імпактний кратер, ударнорозплавлена порода, контракційна тріщина, астероїд.

Y.P. Gurov, V.V. Permiakov

Institute of Geological Sciences of the NAS of Ukraine, Kiev

E-mail: yevgeniy.gurov@gmail.com

\section{CHROMFERIDE IN IMPACT MELT ROCKS \\ OF THE EL'GYGYTGYN CRATER IN CHUKOTKA (RUSSIA)}

The accessory mineralization of chromferide is discovered in impact melt rocks of the El'gygytgyn crater in Chukotka. Impact melt rocks are massive vesicular rocks with a glassy matrix and numerous clasts of shock metamorphosed rocks and minerals of the crater target. Chromferide was crystallized in micron-sized contraction cracks and on the inner surface of gas vesicles. The composition of chromferite in the impact melt rocks corresponds to the composition of reference chromferide and is characterized by the formula $\mathrm{Fe}_{1.5} \mathrm{Cr}_{0.2}$ or $\mathrm{Fe}_{7} \mathrm{Cr}_{1}$. An enrichment of the impact melt rocks of the El'gygytgyn crater in chromium from impacting body was determined earlier. It is supposed that the impactor matter was the main source of chromium in the composition of chromferide.

Keywords: chromferide, impact crater, impact melt rock, contraction crack, asteroid. 